Studies in History and Philosophy of Biological and Biomedical Sciences 45 (2014) 22-33

http://dx.doi.org/10.1016/j.shpsc.2013.11.011

\title{
The mechanistic approach of The Theory of Island Biogeography and its current relevance
}

\author{
Viorel Pâslaru \\ Department of Philosophy, University of Dayton, 300 College Park, Dayton, OH 45469-1546, USA \\ vpaslaru1@udayton.edu
}

\begin{abstract}
Philosophers of science have examined The Theory of Island Biogeography by Robert MacArthur and E. O. Wilson (1967) mainly due to its important contribution to modeling in ecology, but they have not examined it as a representative case of ecological explanation. In this paper, I scrutinize the type of explanation used in this paradigmatic work of ecology. I describe the philosophy of science of MacArthur and Wilson and show that it is mechanistic. Based on this account and in light of contributions to the mechanistic conception of explanation due to Craver (2007), and Bechtel and Richardson (1993), I argue that MacArthur and Wilson use a mechanistic approach to explain the species-area relationship. In light of this examination, I formulate a normative account of mechanistic explanation in ecology. Furthermore, I argue that it offers a basis for methodological unification of ecology and solves a dispute on the nature of ecology. Lastly, I show that proposals for a new paradigm of biogeography appear to maintain the norms of mechanistic explanation implicit in The Theory of Island Biogeography.
\end{abstract}

\section{Keywords}

Mechanistic explanation; Ecology; Island biogeography; MacArthur; Wilson, E. O.

\section{Introduction}

MacArthur and Wilson's The Theory of Island Biogeography (1967), TIB hereafter, had been viewed as a revolutionary work of ecology just a few years after its publication (Cody \& Diamond, 1975; Simberloff, 1974), and maintained this title forty years later (Lomolino \& Brown, 2009; Lomolino, Brown, \& Sax, 2010; Lomolino, Riddle, Whittaker, \& Brown, 2010; May, 2010). TIB is credited with significantly contributing 
toward introducing quantitative, predictive methods to a field that was mostly descriptive and idiographic, consisting of qualitative statements, empirical facts and data that could not be generalized (Cody \& Diamond, 1975; Lomolino \& Brown, 2009; Simberloff, 1974; Whittaker, 1998). In addition, TIB influenced conservation biology to view protected areas as "islands" and introduced new notions to theoretical ecology (Fretwell, 1975; Kolata, 1974; Lomolino \& Brown, 2009; Losos \& Ricklefs, 2010; Whittaker, 1998). The domain of the theory has been expanded to include other island-like ecosystems, including lakes, mountaintops, etc., just as MacArthur and Wilson anticipated (Lomolino, Brown, et al., 2010, p. 24; MacArthur \& Wilson, 1967, pp. 3-4).

In his intellectual autobiography, Wilson characterized biogeography as being in a state of "grand chaos" and "largely descriptive" when he and MacArthur had focused on it in 1961 (1994, p. 244). Its research questions were mostly historical and centered on the origin of the fauna and flora of various regions (MacArthur \& Wilson, 1967, p. 5). The largely descriptive biogeography before MacArthur and Wilson identified two relationships, yet it did not combine them into a unified conception, rather treated them separately. First, the species-area relationship, known since Johann Reinhold Forster described it in 1778 and well documented by several biogeographers, is the tendency of species' numbers to increase with island area. Second, the species-isolation relationship, also known since its description by Forster, is the tendency of species' numbers to decrease with island isolation (Lomolino \& Brown, 2009, p. 15; Lomolino, Riddle, et al., 2010, p. 517). Wilson's study of Melanesian ants identified a third characteristic of insular biotas: species turnover, i.e., immigrations and extinctions as frequent ecological phenomena. The innovation of MacArthur and Wilson was to propose a unifying theory 
that explains the three characteristics of insular biotas in terms of a dynamic equilibrium between immigration and extinction (Lomolino, Brown, et al., 2010, p. 15; Lomolino, Riddle, et al., 2010, p. 520). They substituted "one theory for many facts" (MacArthur \& Wilson, 1967, p. 5). Moreover, they showed that the mathematical expression of the equilibrium model (see Figure 1, subsection 4.1) that is the central piece of the theory could be used to estimate various parameters, such as the mean dispersal distance of a taxon, the degree of saturation of an island whose fauna was displaced from equilibrium, and the necessary time to achieve equilibrium. The graphical form of the model (see Figure 2, subsection 4.1) allowed them to make predictions about changes in immigration, extinction, and turnover rates with area, isolation, severity of climate on island, and with the number of species available in the source area that they verified against data on insular bird faunas (Lomolino \& Brown, 2009, p. 377; MacArthur \& Wilson, 1963, pp. 374-378).

$T I B$ helped create a paradigm that is still influential. Primers of biogeography and ecology still use $T I B$ to introduce basic notions of island biogeography (Gotelli, 2008; Lomolino, Riddle, et al., 2010) and encyclopedias of ecology and of evolution present the ideas of TIB under the rubric of island biogeography (Schoener, 2008; Whittaker, 2002). Although the limitations of this paradigm have multiplied, the new proposals to develop the theory of island biogeography build on TIB nevertheless (Lomolino, Riddle, et al., 2010). The book by MacArthur and Wilson remains highly cited, with more than 3,800 citations just in recent years (2000-2013), from a total of more than 7500 since its 
publication. ${ }^{1}$ This place of $T I B$ in ecology and biogeography warrants the attention of philosophers of science.

Most philosophical analyses of $T I B$ have examined various epistemic aspects of the equilibrium model. In one of the earliest discussions of $T I B$, Haila and Järvinen (1982) view it as a "conceptual framework for the study of insular ecosystems" that has a heuristic role in ecological research. They see the value of the equilibrium model of species numbers in its contribution to understanding the structure and dynamics of populations and communities on islands, rather than in its empirical adequacy. Although the equilibrium model is not empirically accurate, it adds to the conceptual tools of biologists (Odenbaugh, 2011), and its applicability to various domains is an indication of its success (Sismondo, 2000). Kingsland (1995) discusses TIB in the context of history of ecology and conceives of the equilibrium model of species as part of a theoretical effort to steer ecology away from the "natural history phase" and toward becoming more like "physics" focused on repeatable patterns. Continuing this line, Sterelny and Griffiths (1999) argue that $T I B$ is an example of ahistorical ecology focused on identifying patterns and excluding the "noise" of history. Ishida (2007) disputes the interpretation of Sterelny and Griffiths. He argues that mathematical models of $T I B$ explain patterns by identifying underlying mechanisms and shows that $T I B$ does not rule out natural history or historical explanation in ecology. I am sympathetic to Ishida's argument, but his focus on MacArthur ignores the contribution of Wilson to $T I B$, and he does not offer an account of mechanisms described by the mathematical models, nor does he outline a conception of explanation based on descriptions of mechanisms. Schoener (1986) also suggests that the

\footnotetext{
${ }^{1}$ Data from Web of Science database, webofknowledge.com, as of 9 August 2013.
} 
equilibrium model of $T I B$ can be interpreted along mechanistic lines, but does not develop this proposal.

Commentators of $T I B$ have given little attention to the importance of explanation in this theory and its relationship to the goal of transforming biogeography into a predictive science, yet Wilson affirmed this link when he claimed: "I think biogeography can be made into a science. There are striking regularities no one has explained. For example, the larger the island, the more the species of birds or ants that live on it" (Wilson, 1994, p. 248). Thus, for biogeography to become science, it must explain regularities. MacArthur and Wilson ascribed an explanatory role to the equilibrium model from the outset. They first formulated the model in an article published before TIB. There, they present the model as an alternative explanation of the number of species on islands (MacArthur \& Wilson, 1963, p. 374). The fact that $T I B$ was instrumental in creating a paradigm, and considering it as a project focused on explaining the speciesarea relationship, recommends it especially for examining the nature of ecological explanation.

Against this backdrop, I examine the nature of the explanatory approach that MacArthur and Wilson use to articulate $T I B$ and its relevance beyond their project. First, I sketch the conception of mechanistic explanation that I assume (section 2). I consider then MacArthur and Wilson's claims on the nature of scientific inquiry (section 3). In section 4, I analyze $T I B$ using the conception of mechanistic explanation and show that MacArthur and Wilson's approach is mechanistic. More specifically, I examine the reformulations of the explanandum phenomenon and the various models offered to account for it (subsection 4.1). I consider the components of the mechanism responsible 
for various levels of species diversity on islands (subsection 4.2), the causal relations between them (subsection 4.3), their organization (subsection 4.4), and the experimental strategies employed for providing evidence that MacArthur and Wilson use (subsection 4.5). I end with a general statement on the norms of mechanistic explanation in ecology (subsection 5.1); their relevance for resolving a debate on the nature of ecology (subsection 5.2); and the use of the norms of mechanistic explanation in some recent proposals for a new paradigm of island biogeography (subsection 5.3).

\section{Mechanistic explanation}

Bechtel and Richardson offer this concise characterization of mechanistic explanation: By calling the explanations mechanistic, we are highlighting the fact that they treat the systems as producing a certain behavior in a manner analogous to that of machines developed through human technology. A machine is a composite of interrelated parts, each performing its own functions, that are combined in such a way that each contributes to producing a behavior of the system. A mechanistic explanation identifies these parts and their organization, showing how the behavior of the machine is a consequence of the parts and their organization. (1993, p. 17)

The mechanistic perspective on explanation has been subsequently developed by Glennan (1996, 2002), Machamer, Darden, and Craver (2000), Darden (2006), Bechtel (2006; Bechtel \& Abrahamsen, 2005) and many others. The field of mechanistic explanation is thriving, but for my present analysis, I rely on the work of Bechtel and Richardson, who describe mechanistic experimental strategies, and also on the recent development of a normative account of mechanistic explanation by Craver (2007). 
According to Craver (2007, pp. 161-162), a mechanistic explanation needs to satisfy five requirements:

1) Mechanistic explanation must account for the multiple features of the explanandum phenomenon, i.e., including precipitating, inhibitory, modulating, nonstandard conditions, and byproducts.

2) Mechanistic explanations are constitutive in the sense that they explain the mechanism as a whole in terms of the activities of its parts, which should exhibit clusters of properties and could be used for purposes of intervention.

3) Causation in mechanisms consists of activities of component parts.

4) Mechanisms are actively, spatially, and temporally organized.

5) Mechanistic explanation offers an account of constitutive relevance.

Formulation of mechanistic explanations proceeds through a series of models that vary from how-possibly models, which are "loosely constrained conjectures about the sort of mechanism that might suffice to produce the explanandum phenomenon", to howactually models that describe real components, activities, and organizational characteristics of the mechanism that produces the phenomenon. Depending on how complete the models of mechanisms are, they can vary along the continuum mechanism sketch - an incomplete model of a mechanism; mechanism schemata - partial descriptions of mechanism; and complete descriptions of mechanisms (Craver, 2007, pp. 112-114). The regulative ideal of mechanistic explanation is that "constitutive explanations must describe all and only the component entities, activities, properties, and organizational features that are relevant to the multifaceted phenomenon to be explained" (Craver, 2007, p. 111). 
In section 4, I show how the theory of biogeography of MacArthur and Wilson employs this mechanistic approach to explanation. In the next section, I look at MacArthur and Wilson's philosophy of science.

\section{MacArthur and Wilson's philosophy of science}

Commentators of TIB typically refer to MacArthur's writing to understand the philosophy of science underlying this major work of ecology. Wilson's contribution has not received the same attention, although his work contains important statements on the issue. I examine first the view of MacArthur and then I turn to that of Wilson, insisting in both cases on their commitment to a mechanistic approach to doing science.

\subsection{MacArthur's philosophy of science}

One of the ideas that characterizes MacArthur's view on the nature of scientific inquiry, in contrast to his predecessors in biogeography, is that "[t]o do science is to search for repeated patterns, not simply to accumulate facts", and ecology should formulate general principles that apply across species (MacArthur, 1972, p. 1) and that unify thus a variety of phenomena. MacArthur complements the distinction between the search for repeated patterns and accumulation of facts from nature's complexity with a distinction between two explanatory approaches. One could investigate the history of a phenomenon, or describe "the machinery of the phenomenon", or its mechanism, as one would call it today. The ecologist and the physicist tend to be machinery oriented, but the 
paleontologist and most biogeographers tend to be history oriented. The historian often pays attention to differences between phenomena, since this may shed light on history. By contrast, the "machinery person" is more focused on similarities among phenomena, because these reveal regularities (MacArthur, 1972, p. 239). Since investigating "the machinery of the phenomenon" reveals what produced it, to explain regularity, one needs to describe the mechanism that brings it about. That description of ecological mechanisms is explanatory is MacArthur's second idea on the nature of ecological inquiry. Consequently, he urged biogeographers to be more machinery oriented.

Here are a few examples that illustrate the importance of the notion of machinery, aka mechanism in MacArthur's work. Competition and predation are common and regular processes that are also produced by machinery. This is evidenced by the title The Machinery of Competition and Predation of the second chapter of his 1972 book. MacArthur explains that it is difficult to define competition because "the machinery is not obvious", but some ecologists list "various competitive mechanisms". He prefers a broad definition of competition such that "[a]ny machinery that can have that effect will be called competition. For instance, species A and B can fight, or A can reduce B's food supply, or A can, by its own losses, increase B's predators” (MacArthur, 1972, p. 21). In Geographical Ecology (1972), he examines several cases that "reveal interesting things about the mechanisms involved" (p. 78) and mentions that there is a populationregulating mechanism that prevents a population from consuming entirely its food supply (p. 119). Additionally, MacArthur offers examples of mechanistic explanation of various phenomena. For example, he uses the work of C. Smith that explains the distribution of two squirrel species by referring to their anatomy, food preferences and availability in 
geographic areas, as well as other properties (MacArthur, 1972, pp. 140-141). MacArthur explains the low diversity of tree species in Europe compared to that in North America by referring to the advancing glaciers that are "the actual machinery" that pushed species to the south. The north-south orientation of mountains in America allowed trees to retreat to the south, while the west-east orientation of the Alps and of the Mediterranean did not allow trees to escape the pressure of glaciers. This arrangement of the mountains and of the sea is an historical accident requiring an historical explanation, while the advancement of the glaciers is the mechanism common to both cases (MacArthur, 1972, p. 174).

The third idea of MacArthur's view on ecology is that ecologists must use the hypothetico-deductive (H-D) method. He argued that the method of fitting statistical curves of vague biological meaning to the data should be replaced with the more fruitful approach of predicting curves based on simple biological hypotheses and to compare them with the data (MacArthur, 1957, p. 293).

\subsection{Wilson's philosophy of science}

Looking back forty years after its publication, Wilson recalls the founding questions that he and MacArthur asked (2009, p. 5):

How could our seemingly old-fashioned subjects (i.e., ecology and evolutionary biology - V.P.) achieve new intellectual rigor and originality compared to molecular biology? What can we learn from molecular biology on how to advance our own science? We agreed that the basic 
problem was that ecology and evolutionary biology were mostly unrooted. They needed foundations from which explanations can be developed bottom-up. Theory has to work from lower to higher levels of biological organization. Either alone will not do. Population biology was the discipline we thought could serve as base to reinvigorate the theory of ecology and evolutionary biology. (Such was the line of reasoning by which I later produced the first syntheses of sociobiology, in The Insect Societies, in 1971, and Sociobiology: The New Synthesis, in 1975.)

Wilson's recollection indicates two foundational ideas of his philosophy of science: reductionism and the hypothetico-deductive method, which I examine successively. The early advances and success of molecular biology had lead Wilson to claim: "I believed deeply in the power of reductionism" (Wilson, 1994, p. 255). Yet he did not mean philosophical reductionism, as he called the intertheoretic reductionism illustrated by Nagel's classical account. According to Nagel, a less inclusive theory is absorbed into, or deduced from a more comprehensive theory plus theorems derivable from it, experimental laws, observation statements and some laws borrowed from other special disciplines when instruments are involved (Nagel, 1961, p. 349). Following Popper (1974), Wilson thought that philosophical reductionism is wrong. The upper-level of organization contains principles that are "new and unexpected" and so cannot be derived from the principles of the lower-level science. The laws of the lower-level science "are necessary to the discipline above, they challenge and force a mentally more efficient restructuring; but they are not sufficient for its purposes" (Wilson, 1977, pp. 137-138). Instead of conceiving of reduction as deduction of one theory from another, 
Wilson thought "[r]eduction is a method by which new mechanisms and relational processes are discovered" (1978, p. 13). He also characterized reductionism as naturalism and that in his sociobiological research meant bringing biology into the social sciences (Wilson, 1994, p. 225), but without claiming that biology can explain away the social sciences.

Wilson's sociobiological research further shows that his belief was not in the power of intertheoretic reductionism, but it was about methodological and explanatory reductionism. In The Insect Societies, Wilson claims that partial explanations of social phenomena consist of descriptions of proximate causes in physiology and behavior, combined with the theory of ultimate causes due to colony-level selection. A more nearly complete explanation requires in addition the population ecology of colonies (Wilson, 1971, p. 426). Yet not even the partial explanation fits the classical reductive account. Descriptions of physiological and behavioral causes and the theory of group selection do not form a more inclusive theory, but separate epistemic approaches. Adding population ecology to formulate a nearly complete explanation does not make for intertheoretic reduction, since the same problem of separate epistemic approaches persists. Even if evolutionary biology were the reducing science, the descriptions of physiological and behavioral causes are not borrowed laws from other sciences. Furthermore, intertheoretic reductionism requires reducing theories to describe phenomena at a different level than those studied by the reduced theory. However, population parameters that would be part of the reducing theory are situated on the same stratum that contains the very social phenomena whose theory is supposed to be reduced. 
Wilson explains that some sociobiological research involves phenomenological and fundamental theories. Phenomenological theory consists of equations that predict various parameters of social organization, while the fundamental theory derives the equations from principles of genetics and ecology (Wilson, 1978, p. 28). Despite the relationship between the two types of theories being formulated in terms of derivation, this is not evidence of intertheoretic reductionism. Genetics and ecology are different disciplines that characterize entities at different levels, but intertheoretic reductionism requires the reducing theory to refer to entities at the same level.

Wilson's claims about reductionism could be understood as a commitment to methodological and explanatory reductionism in a weaker sense. Higher-level phenomena ought to be explained in terms of mechanisms and processes at various lower levels, but not at some fundamental level. Sociobiological research by Wilson shows that explanation is a multilevel approach, integrating findings from genetics, ecology, studies of the environment, animal behavior and physiology, and evolution. This is also the path that Wilson followed in conceiving of evolutionary biology (Wilson, 1994, p. 226).

Wilson's research in sociobiology also indicates that unification is a virtue that he expected good theories to have. Outlining how sociobiology should develop, he explains that a unified science of sociobiology should produce quantitative theory and parameters that apply to both termite colonies and troops of rhesus macaques (1971, p. 458). It is an expectation that resonates well with MacArthur's thought that the general principles of science should unify phenomena; they should apply to both Paramecium and birds (1972, p. 1). 
MacArthur is credited with impressing the hypothetico-deductive method on ecologists, yet Wilson's work contains explicit formulations of the method that, according to his recollection, underlies $T I B$. In both of his aforementioned books on sociobiology, Wilson describes the hypothetico-deductive method that he uses. ${ }^{2}$ Here is a statement from the Sociobiology: "Above all, good theory is testable. Its results can be translated into hypotheses subject to falsifications by appropriate experiments and field studies" (Wilson, 2000 [1975], p. 27). TIB affirms this commitment to the hypotheticodeductive method when it claims: "A theory attempts to identify the factors that determine a class of phenomena and to state the permissible relationships among the factors as a set of verifiable propositions" (MacArthur \& Wilson, 1967, p. 5).

The foregoing analysis shows that Macarthur and Wilson had similar views on the nature of scientific inquiry, with the concept of mechanism playing a central role. Explanation of biogeographic phenomena consists in description of mechanisms producing those phenomena. Descriptions of mechanisms also underlie hypotheses that are used to make predictions tested against empirical data. Hypotheses that are not rejected support our confidence in the purported mechanism. When the same mechanism produces multiple instances, their "unity lies in the pervasiveness of the underlying mechanism [s] upon which we depend for explanation" (Salmon, 1984, p. 276) and its description would be part of a theory that unifies that variety of cases. In the next section, I examine how $T I B$ implements the mechanistic conception of explanation.

\section{Mechanistic explanation in The Theory of Island Biogeography}

\footnotetext{
${ }^{2}$ See Wilson (1971, 2-3, 458-460); chapter 17 illustrates application of the method (Ibid., 328-334); Wilson (2000 [1975], 27-31).
} 
TIB contains few references to mechanisms. However, based on the normative account of mechanistic explanation by Craver (2007) and the work of Bechtel and Richardson (1993) on the mechanistic experimental strategies, I show that MacArthur and Wilson apply the mechanistic approach to explain the diversity of species on islands, and the regular relationship between species' numbers, i.e., their diversity and the area of island.

\subsection{The explanandum phenomenon}

MacArthur and Wilson's first formulation of the explanandum of the theory of biogeography is diversity of species on islands, which are understood broadly as any isolated area. ${ }^{3}$ The problem is to explain why there is a certain number of species on an island and why there are certain species rather than others on the island. The first explanation of species diversity is formulated in terms of an equation:

(1) $S=C A^{z}$,

where $S$ is the number of species, $A$ is the area, $C$ is a parameter that varies with the taxon and biogeographic region, and $z$ is a constant. Thus, the number of species on an island depends on area, $C$ and $z$. The larger is the area of an island, the greater is the number of species on that island.

MacArthur and Wilson do not see area as a determining factor and explanans of the number of species on islands "because area seldom exerts a direct effect on a species'

\footnotetext{
${ }^{3}$ That diversity of species is the explanatory focus of MacArthur and Wilson is evidenced, for instance, by the claim "Our ultimate theory of species diversity..." (MacArthur and Wilson, 1967, p. 8. Italics added for emphasis - V. P.).
} 
presence", such that the theory of species diversity may not mention area (MacArthur and Wilson, 1967, p. 8). Rather, "[m]ore often area allows a large enough sample of habitats, which in turn control species occurrence" (MacArthur and Wilson, 1967, p. 8). Equation (1) is a how-possibly model, sensu Craver. It conjectures the mechanism of species diversity in the form of a regular relationship between changes in numbers of species given changes in area. The equation approximates the regularity, but is not sufficiently explanatory. The regularity itself requires an explanation. Because of this, MacArthur and Wilson change the explanandum from diversity of species on islands to orderly relationship between island area and species diversity. That the latter is the explanandum is evidenced by the very title of the third chapter of their book - Further Explanations of the Area-Diversity Pattern (MacArthur and Wilson, 1967, p. 19).

A central piece of the explanans of the orderly relationship between island area and species diversity is a model of the underlying mechanism and it comes in two versions. The first version of the model (Figure 1) accounts for species diversity as an equilibrium between emigration and extinction. 


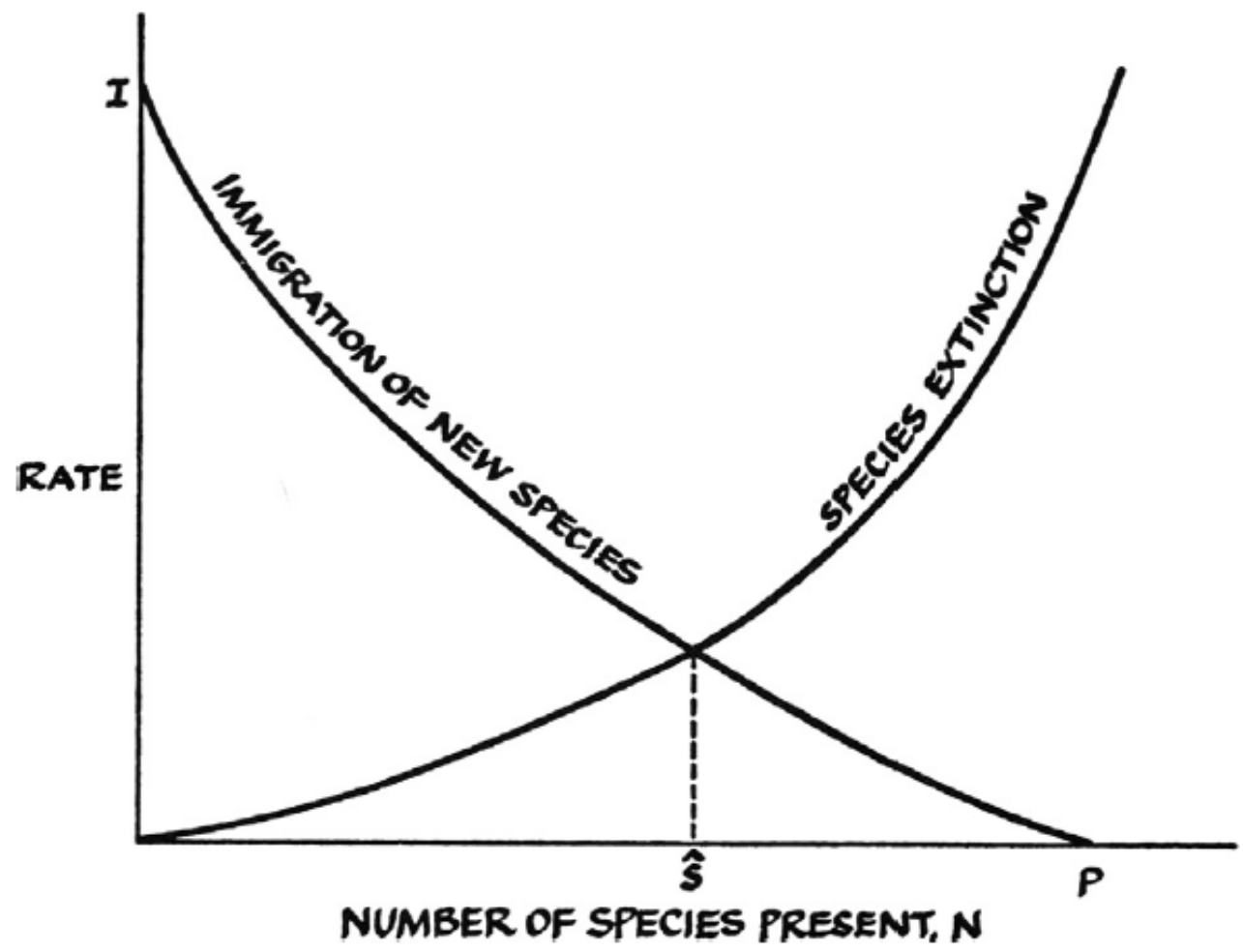

Fig. 1. Equilibrium model of species diversity. From MacArthur, R. H., and Wilson, E. O. (1963). An equilibrium theory of insular zoogeography. Evolution, 17, 373-387; published by John Wiley \& Sons. Reprinted by permission of John Wiley \& Sons, Ltd.

The immigration rate decreases because fewer immigrants belong to new species as more species become established. If more species are present on the island, then more are going to go extinct. Extinction balances out immigration and so the number of species is at equilibrium. This model is a mechanism sketch of the actual mechanism. It describes real processes, immigration and extinction, but it does not represent how size of island and its distance from the mainland affect the equilibrium number of species. This weakness of the immigration-based model prompts MacArthur and Wilson to propose a more realistic model, depicted in Figure 2, that takes into account these factors. 


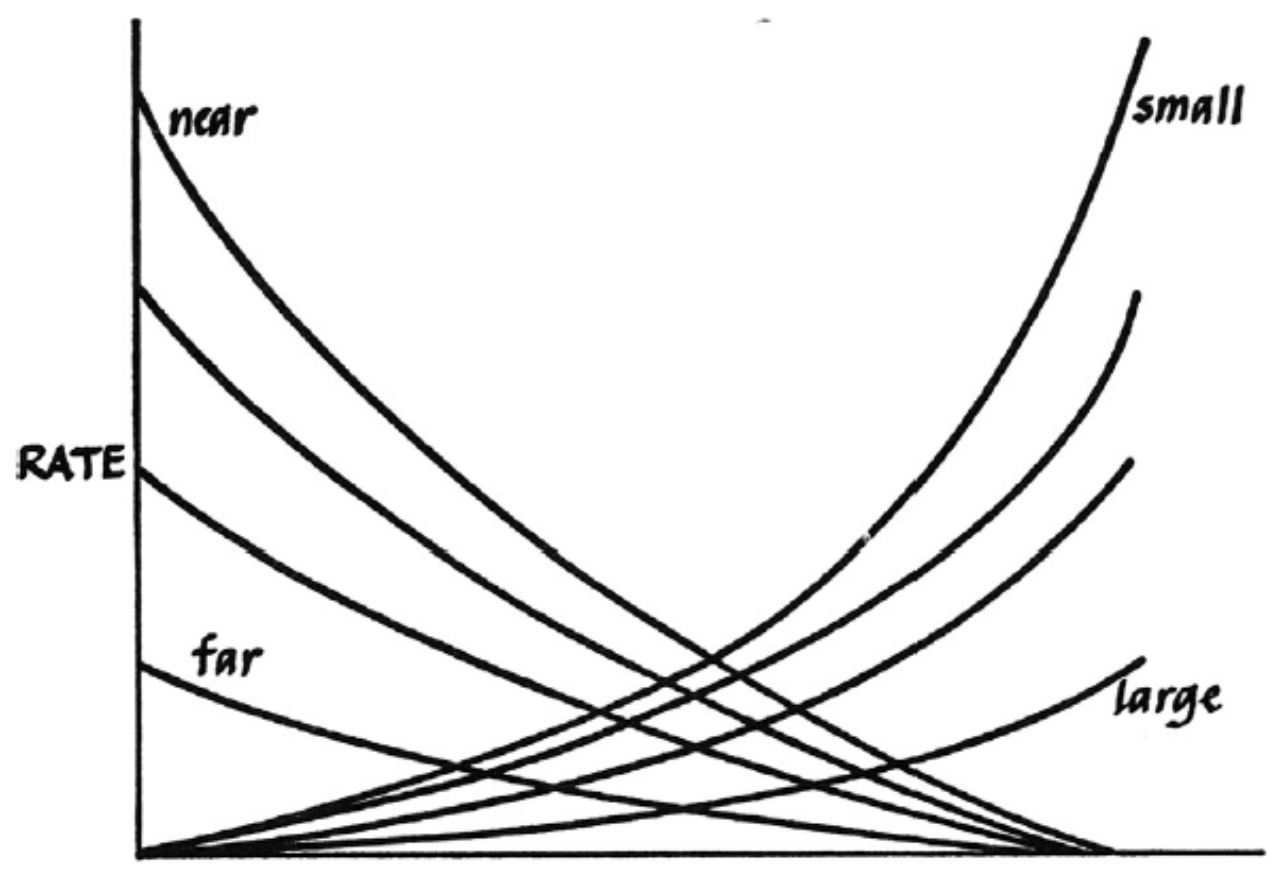

NUMBER OF SPECIES PRESENT, $\mathbf{N}$

Fig. 2. Various equilibrium points of species diversity depending on area of islands and their distance from the source region. From MacArthur, R. H., and Wilson, E. O. (1963). An equilibrium theory of insular zoogeography. Evolution, 17, 373-387; published by John Wiley \& Sons. Reprinted by permission of John Wiley \& Sons, Ltd.

This second model is a mechanism schema, likewise in the sense of Craver. It is a more complete description of the mechanism, since it encompasses size of island and its distance to mainland in addition to immigration and extinction. Proximity to the source region increases the immigration rate, while a decrease in the area of the island increases the extinction rate. The various levels of the equilibrium number of species are due to various combinations of different sizes of islands and their distances to the source region. This model also represents more accurately the explanandum as various equilibria of species numbers on islands of various sizes and situated at different distances from the mainland. Based on this model, MacArthur and Wilson formulate several models to 
explore how changes in the modulating conditions, i.e., variations in island size and in distance to the source region; presence of stepping stones; and islands forming archipelagos affect species diversity on islands (1967, 27-32).

Table 1 (Figure 3) from the introductory chapter of $T I B$ is another schema, and an important one, as I will show, of the mechanism of species diversity on islands. ${ }^{4}$ Commentators of $T I B$ have not discussed it. ${ }^{5}$

TABLE 1. Interrelations of chapters

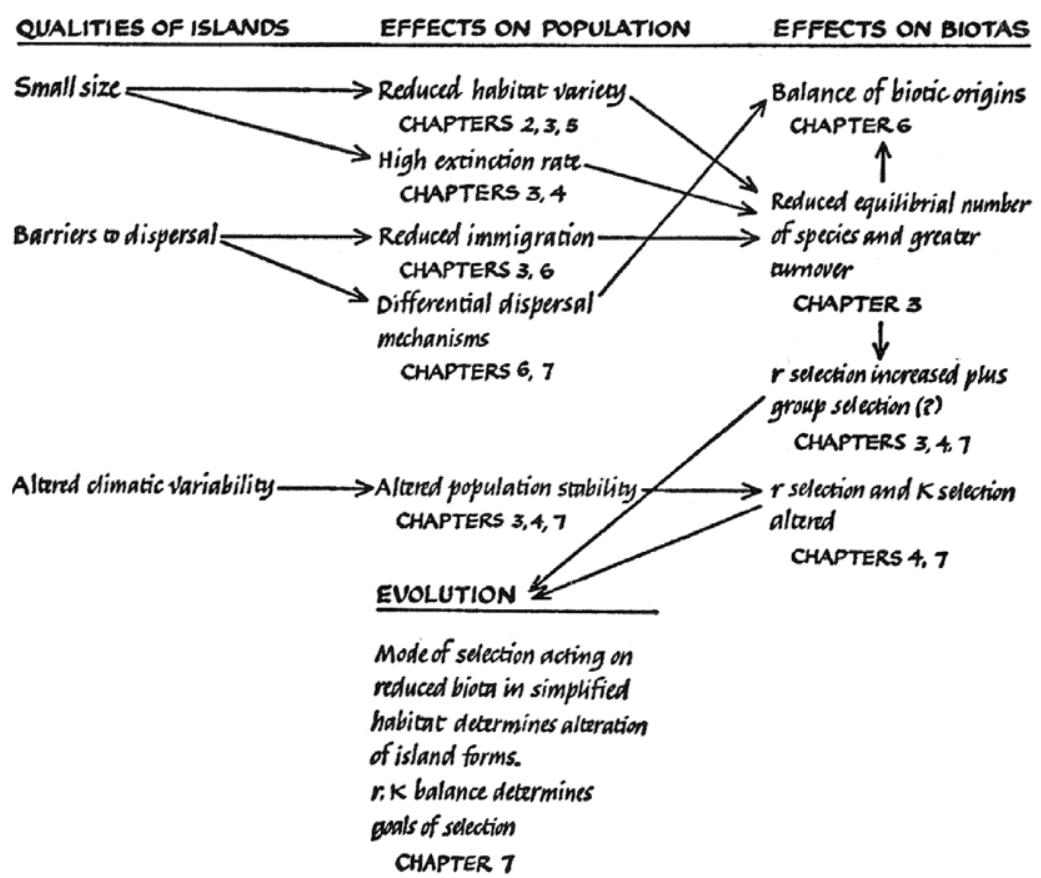

Fig. 3. Interrelations of topics and sequence of causation. From MacArthur, R. H. and Wilson E. O.; The Theory of Island Biogeography. ㄷ 1967 Princeton University Press; auto renewed. Reprinted by permission of Princeton University Press.

\footnotetext{
${ }^{4}$ Values 'small' and 'reduced' of variables 'size,' 'habitat variety' and 'equilibrial number of species' indicate that the table describes only the case of small islands. A table for islands of other sizes would not contain new variables, but only different values. For example, there would be 'large' size, 'high' habitat variety and 'low' extinction rate. ${ }^{5}$ For example, Kingsland's (1995) discussion of TIB focuses only on the first model, Figure 1. Ishida (2007) and Odenbaugh (2011) consider only the equation form of the equilibrium model (equation 1) and its developments. Sismondo (2000) refers to the first two graphical models, Figures 1 and 2, as well as to equation 1.
} 
MacArthur and Wilson say about this table that it "shows the sequences of causation as we conceive them and their location as topics in the next six chapters of the book" (1967, p. 7). This table is not just a plan of the book. The reference to "the sequence of causation" suggests that the table is a causal graph in the sense used in the literature on causal modeling (Pearl, 2000; Spirtes, Glymour, \& Scheines, 2000) and on casual explanation (Woodward, 2003). Causal graphs consist of nodes linked by directed edges, and nodes represent variables. Upper case letters commonly designate nodes. Causal relationship between $\mathrm{X}$ and $\mathrm{Y}$, in which $\mathrm{X}$ causes $\mathrm{Y}$, is represented by the following causal graph: $\mathrm{X} \rightarrow \mathrm{Y}$. Instead of upper case letters, the table uses verbal expressions to designate causal factors, but the directed edges represent the causal relationships. Given how the table is articulated and given MacArthur and Wilson's explicit admission that the table shows the sequence of causation, it follows that the table is a causal graph. And the graph represents the causal structure of the mechanism responsible for the orderly relationship between various levels of species diversity on islands and their area, and how this structure, together with climatic variability, has an effect on evolution.

The equilibrium model (Figure 2) that has been the main focus of most commentators of $T I B$ refers to species numbers, island area, immigration, extinction, and distance to the source region as factors determining species' numbers at equilibrium. The equilibrium model captures mathematical dependencies, which cannot be identified with causal or explanatory dependency relations. The mathematical dependencies, by themselves, are not explanatory. To be explanatory, a causal interpretation must complement the model that captures mathematical dependencies (Craver, 2006, p. 365). And it is the causal graph depicted in the table that expresses the causal interpretation. It 
specifies which variables represent causes and which stand for effects. In addition to all the variables of the equilibrium model, the causal graph contains habitat variety and barriers to dispersal, which comprise stepping-stones, distance to the source region and whether islands are clumped. Compared to the equilibrium model, the causal graph represents all the factors that MacArthur and Wilson see as responsible for species diversity. As such, it is more realistic than the previous ones and is a more complete description of components of the mechanism and of relationships between them. Additionally, the causal graph indicates that the product of this mechanism, equilibrium number of species and turnover rate is causally linked to $r$ selection that together with climatic variability and $K$ selection ultimately affect evolution. The upshot is that to describe a mechanism, it is necessary to use several models, each of which sheds light on some aspect of the mechanism and together they offer a complete description. To paraphrase Levins (1966), a complete description of the mechanism is at the intersection of several models.

\subsection{Constitutive aspect}

A good mechanistic explanation identifies real components that satisfy four criteria: (1) components have a stable cluster of properties, (2) are robust, (3) can be used to intervene onto other parts and activities, and (4) are plausible in a given pragmatic context (Craver, 2007, pp. 131-133). The causal graph indicates the components of "the machinery" responsible for the species-area relationship. They are islands, source region and populations of different species, and they satisfy these criteria. 
First of all, a caveat on source region: neither the equilibrium models nor the causal graph represent it, and MacArthur and Wilson do not examine it in as much detail as islands, yet one can infer from the role of the source region in accounting for the equilibrium number of species on islands that it is a component. First, immigration to any island originates from a source region. Without immigration from a source region, no species diversity on any island is possible. Second, whether an island is far or near relative to a source region affects immigration. The source region is, hence, a necessary component for determining the rate of immigration and the number of species on islands. Third, any island that immigration originates from functions as a source region. Since islands are components of the "machinery", the source region is a component as well.

All three aforementioned components have stable properties, and some of them receive extensive attention in $T I B$. A stable property of islands is area, habitat variety being another one. While the equilibrium model does not mention the latter, the causal graph shows that changes in size change habitat variety. Traits of species receive ample attention. MacArthur and Wilson examine in detail which properties of species are relevant for successful colonization and immigration. At the population level, it is birth and mortality rates, the intrinsic rate of population growth and efficient utilization of resources. They do not leave the investigation of properties of populations at this general level that is suitable for modeling. Instead, MacArthur and Wilson list the specific attributes of species that make them good colonizers (MacArthur and Wilson, 1967, pp. 80-83). For example, birds that are good colonizers and have high intrinsic population growth rates tend to fly in small flocks, while birds that efficiently utilize resources are able to occupy many habitats and tend to eat seeds. Plants that have fast individual 
development, large quantities of progeny and occasionally self-pollinate are good colonizers and have high population growth. Some species prefer stable habitats, while for others unstable habitats are necessary to flourish. These, as well as other properties of organisms differently determine the immigration and extinction rates, and the colonization process, under the same conditions. A similar attention to ecological details of community structure on islands and to morphological and behavioral properties of species helps explain the invasibility of islands (MacArthur and Wilson, 1967, pp. 94104). This analysis of colonization and immigration in terms of the life history properties of species, which are components of these processes, rather than simply measuring and modeling these processes, indicates the mechanistic approach.

The robustness criterion requires that a variety of causally and theoretically independent devices should be used to detect parts and to provide evidence for their existence (Craver, 2007, p. 132). MacArthur and Wilson used causally and theoretically independent sources of evidence to determine that island size indeed influences the level at which species equilibrate. In particular, they used evidence from past recordings of species diversity on islands of the West Indies, of the Dry Tortugas, and field experiments on artificial islands (subsection 4.5 develops this aspect).

Consistent with the third criterion of real components, MacArthur and Wilson modified size, distance and configuration of islands in the equilibrium model to explore how such modifications affect the equilibrium number of species (MacArthur \& Wilson, 1967, pp. 27-31). However, such interventions are not restricted to the domain of modeling, but are possible and take place on real islands and can be used to intervene onto other parts and activities. Environmental and anthropogenic factors routinely 
change, even if oftentimes at very slow pace, the size and habitat of various islands and of source regions. Shortly after the publication of $T I B$, Wilson and Simberloff (Simberloff \& Wilson, 1969, 1970; Wilson \& Simberloff, 1969) published results of a field experiment intended to test the theory. They set the density of faunal populations to zero by fumigating several islands (more on this experiment in subsection 4.5). Thus, they manipulated density of faunal populations - which are parts - to change equilibrium number of species, colonization and extinction rates, which are parts and activities respectively.

The criterion of plausibility requires that "the parts' existence should be demonstrable under the conditions relevant to the given request for explanation of the phenomenon" (Craver, 2007, p. 132). Given that "area seldom exerts a direct effect on a species' presence" (MacArthur and Wilson, 1967, p. 8), it does not seem to be a plausible ecological factor that by itself could have an explanatory role; hence, MacArthur and Wilson's shift from $S=C A^{z}$ to models based on the ecological processes of immigration and extinction. Nevertheless, area is plausible as an indicator of an island's diversity of habitats and its ability to accommodate a certain number of species. Because of this, it is maintained as a main property of islands.

MacArthur and Wilson talk about stepping-stones as if they were a separate type of component. However, stepping-stones are just islands. Whether these islands function as stepping-stones depends on their location between source region and another island, and so they do not need to be treated as a separate type of component. 


\subsection{Causal relations and activities}

"Activities are the causal components in mechanisms", and they can be used for manipulation and control in the sense of Woodward's (2003) conception of causation (Craver, 2007, p. 6). Properly organized productive activities of components are responsible, at least partly, for producing the explanandum phenomenon, so a mechanistic explanation must describe them. Verbs and verb form (participles, gerundives, etc.) offer a guide for identifying activities (Machamer et al., 2000, p. 4). Consistent with this view, MacArthur and Wilson's approach contains numerous descriptions of activities of components. For example, considering the recolonization of the Krakatau islands after a volcanic eruption destroyed the entire flora and fauna, they note about certain birds that they "colonized three islands," "appeared on the islands," while others have not "established as breeding populations," or "disappeared." Yet another species was "brooding" (p. 47). The description of a good colonizer contains references to a number of activities. For example, birds tend to "fly long distances," they "clump" and "occupy many habitats," and tend to "eat seeds." Plants "constantly colonize newly opened habitats," and it is indicated that they self-pollinate, and produce propagules, while ants exhibit the trait—of unknown significance—of laying odor trails (MacArthur and Wilson, 1967, p. 81). And all species must somehow traverse the space between the source region and the destination island. Most importantly for the explanatory role of activities is that the equilibrium models represent the processes of 
immigration and extinction, which, in their turn, indicate activities of migrating and dying out. ${ }^{6}$

Not all activities are easily visualized like the aforementioned, yet they are productive of changes and can be used for manipulation and control in the sense of Woodward's (2003) conception of causation: if there is a possible intervention on $X$ that changes the value of $Y$ or the probability distribution of $Y$, while all other variables are held fixed, then $X$ causes $Y$. Decreasing the distance between island and source region reduces immigration and extinction, and increasing the distance declines immigration and extinction rates. Changes in immigration and extinction change the equilibrium number of species. Similarly, increasing area of an island increases immigration and extinction and the equilibrium number of species. The causal graph (Figure 3) indicates causal relations of this kind. For example, a small island size reduces habitat diversity, yet the size of the island does not manifest any obvious activity, nor does the high extinction rate that reduces equilibrial number of species. These productive activities establish relationships that are causal in that they are exploitable for manipulation and control. ${ }^{7}$

\subsection{Organization}

Organization of components in a mechanism distinguishes them from aggregates, and the mechanistic explanation wants to capture that organization (Bechtel and Richardson, 1993; Craver, 2007). Components form a mechanism provided that they do not make up

\footnotetext{
${ }^{6}$ Italics added throughout for emphasis - V. P.

${ }^{7}$ For a more detailed argument for linking activities and relationships exploitable for manipulation and control based on a different ecological case see Pâslaru (2009).
} 
an aggregate, which Craver characterizes based on a definition by Wimsatt (1997):

assuming that a property or activity $\mathrm{A}$ of the whole $\mathrm{S}$ is explained by the properties or activities $\mathrm{P}$ of its parts $\mathrm{X}_{1}, \mathrm{X}_{2}, \ldots, \mathrm{X}_{\mathrm{m}}, \mathrm{A}$ property of $\mathrm{S}$ is an aggregate of $\mathrm{P}$ properties of X's when:

(W1) InterSubstitution: A is invariant under the rearrangement and intersubstitution of Xs;

(W2) Size Scaling: A remains qualitatively similar (if quantitative, differing only in value) with the addition or subtraction of Xs;

(W3) Decomposition and ReAggregation: A remains invariant under the disaggregation and reaggregation of Xs; and

(W4) Linearity: There are no cooperative or inhibitory interactions between Xs that are relevant to A (modified after Craver, 2007, p. 135, and Wimsatt, 1997, p. S376).

The mechanism of the species-area relationship does not satisfy any of these conditions. Plants are early colonizers and herbivores are late colonizers, and species migrate to islands from source region, and they cannot be intersubstituted or rearranged, contrary to (W1). This is because plants create the conditions for herbivores to get established, and source region contains the pool of species, but not vice versa. The mechanism does not remain qualitatively similar with the addition or subtraction of parts. Subtraction of either the source region, or island, or populations disrupts the functioning of the system. Source region is required for species to originate from, and islands are necessary for species to migrate to. Hence, condition (W2) for aggregativity is not met. It is not possibly to take the mechanism apart and then put it back together, as required by (W3), without disrupting their collective ability to produce the orderly relationship 
between species' numbers and area. Separating some components, islands or source region, destroys the system. The effect of separating populations of species depends on whether their role in the island community can be compensated. If the role of a species cannot be substituted, its removal disrupts the functioning of the mechanism and reaggregation is problematic. As for condition (W4), it is not satisfied because of the cooperative and inhibitory interactions between components, especially between populations. Seeds need birds to colonize islands, and herbivores need plants to survive. Established species predate on or compete with newly arriving species, or with the established ones, which leads to extinction or inhibition of population growth.

The mechanism of species diversity is spatially and temporally organized. Size of islands, their location relative to source region, and whether stepping-stones connect islands and the source region are important for constituting the mechanism. Islands that are too small for species, say, insects, birds, or plants, to populate them and islands that are located at a distance that exceeds their ability to reach them will not receive immigration; hence, there will be no species diversity on these islands. Stepping-stones connecting islands increase immigration rate, but if stepping-stones are numerous and organized in a manner that creates a corridor between the island and the source region, the species dynamics on that island will be assimilated to that on the mainland. The order and rates of immigration and extinction determine the relationship between species' numbers and area. Succession following a major environmental event, say, a volcanic eruption that wipes out the flora and fauna, has a specific order. Pioneer plants colonize the barren island first. Plants of secondary succession and then trees follow them (MacArthur and Wilson, 1967, p. 50). Trees cannot colonize an island before pioneer 
plants. If the rate of immigration is too low, species' numbers on islands will be below the expected equilibrium point. A similar outcome would occur if rates of extinction were too high, say, because tsunamis often strike the island.

\subsection{Constitutive Relevance}

Bechtel and Richardson (1993) and, following them, Craver (2007) argue that two types of experimental interventions are required to identify the relevant functions and components in a system. The analytic, or bottom-up interventions inhibit or stimulate the functioning of a component. Alternatively, one could also increase or decrease the quantity of that component. If the component intervened upon is important for the functioning of the system, the intervention will change the behavior of the system. The top-down experiments, or synthetic strategy, make the system perform a function and one examines which component parts become active. Additionally, one could create a model system based on a hypothesis regarding the components, their operations and organization that are required for its functioning and then compare the behavior of the model system with that of the real one. If both bottom-up and top-down experimental interventions yield convergent results, the component subject to intervention is a relevant one for the system to produce the phenomenon under scrutiny.

To support their explanation of the species-area relationship, MacArthur and Wilson use evidence that presupposes both the analytical and synthetic experimental strategies. Examining the second equilibrium model (Figure 2), they suggest a number of interventions on islands. Increasing the degree of isolation between the island and the 
source region reduces immigration. Intervening to decrease the area of the island increases extinction rate (MacArthur and Wilson, 1967, pp. 22-23). They also examine four cases of species distribution that vary due to changes in island area, distance between islands and source region, and configuration of islands (MacArthur \& Wilson, 1967, pp. 27-32). Each of the models of those cases presupposes the use of inhibitory and excitatory techniques of the bottom-up experiments. In what would amount to a thought experiment executed by modifying the variables of models, MacArthur and Wilson intervene and increase the distance between archipelagos and their source region (MacArthur \& Wilson, 1967, p. 28, figure 12), or between some islands and the source region (MacArthur \& Wilson, 1967, p. 31, figure 15). These modifications are analogous to excitatory interventions, for they increase the entity that separates islands from the source region. Size of stepping-stones (MacArthur \& Wilson, 1967, p. 29, figure 13) and distances between islands forming an archipelago (MacArthur \& Wilson, 1967, p. 31, figure 15) are also manipulated.

MacArthur and Wilson use observational data from various replicates, i.e., islands, in a manner that illustrates another way of applying the excitatory technique in thought experiments. Comparing data on densities of species on several islands of the Dry Tortugas of roughly the same area, they found out that an increase in species' numbers on islands of roughly the same area increases the extinction rate (MacArthur and Wilson, 1967, pp. 51-55). Using replicates of these islands amounts to an experiment in which density of species is increased to various levels to elicit its effect on extinction rate, while the area remains unchanged. 
MacArthur and Wilson also employ evidence from experiments performed by other ecologists. These experiments can be seen as top-down experiments, or as applications of the synthetic strategy. In particular, the design of these experiments assumes a hypothesis about the process of island colonization, formulates a model of how the system that underlies this process functions and then tests the model against the behavior of actual systems, just as Bechtel and Richardson (1993) and Craver (2007) describe the synthetic strategy. Put differently, the system is set to operate and the experimenter examines which components are activated. One such experiment was performed by Bassett Maguire, Jr. who simulated islands by using bottles of fresh water placed at various distances from a fresh water pond and at various heights above the ground. In agreement with the equilibrium model, the colonization curve drops as distance from the source region increases. The design of this experiment assumes the hypothesis that distance from the source region is a determinant of species' numbers on islands (MacArthur and Wilson, 1967, pp. 42-43). Another experiment to which MacArthur and Wilson refer is due to Ruth Patrick. She suspended small glass slides of two sizes in the water of a spring and then counted and identified the attached diatoms after every two weeks. The design of this experiment assumes the hypothesis that islands of larger areas accommodate a greater number of species. The data shows indeed that "islands" of large area hold more species than small ones, and that the competition that begins once the diatoms become crowded reduces the number of species (MacArthur and Wilson, 1967, pp. 55-57).

MacArthur and Wilson did not perform experiments using the analytic and synthetic strategies to test their theory, but Simberloff and Wilson did. To test certain 
aspects of the theory of island biogeography, they fumigated six small mangrove islands in the Florida Keys to defaunate them and then monitored for two years how faunal species recolonize the islands. The islands were ultimately recolonized and the faunal species reached a dynamic equilibrium as expected in light of the theory of island biogeography (Simberloff \& Wilson, 1969, 1970; Wilson \& Simberloff, 1969). To the extent that the experiment decreases to zero the amount of one component - faunal species - it implements the analytic inhibitory strategy. In the absence of faunal species, no equilibrium of such species can occur, which shows that faunal species are a relevant component of the "machinery." However, the significance of this experiment is better assessed if it is seen as implementing the synthetic strategy. Islands are model systems aimed to test hypotheses about equilibrium of species, colonization processes, and the role of island area and distance from the source region in influencing these processes. Considered from this point of view, defaunation initiates colonization and the experimenter examines the process of colonization, the number of species at which immigration and extinction equilibrate, and the role of island area and distance from the source region in affecting these processes.

\section{The Message of The Theory of Island Biogeography beyond 1967}

Having significantly contributed to the initiation of a paradigm of ecology in general and of island biogeography in particular, $T I B$ is a canonical example to identify the norms of scientific explanation in ecology and to examine how the focus on mechanisms can help solve other debates in ecology. I outline first an account of the norms of ecological 
explanation based on the analysis from section 4 , and then I show how the notion of mechanism could resolve a debate from ecology. I also show that even if the equilibrium paradigm of $T I B$ were to be changed, the norms of mechanistic explanation in ecology will be used to account for ecological phenomena within the next paradigm of insular biogeography.

\subsection{An account of explanation in ecology}

It can be learned from $T I B$ that to explain in ecology is to describe the mechanism of a phenomenon under scrutiny and that this description can extend over several levels and comprise several models that represent various aspects of the mechanism. The explanandum phenomenon has multiple aspects and the mechanistic explanation must account for all of them. Ecological phenomena are produced under conditions that modulate, precipitate, or perturb their production, or they could occur in non-standard conditions. Description of the putative mechanism must show how it produces the explanandum phenomenon in all these conditions. Changes in the size of islands, their distance to the source region and their organization in archipelagos modulate the areadiversity relationship. Predation modulates competition, and changes in temperature and moisture modulate colonization. A very small size of islands perturbs the area-diversity pattern, but so do disease and parasitism that perturb population growth. Cataclysms, such as volcanic eruptions, precipitate the formation of the area-diversity pattern, and the introduction of lynxes in a hare habitat precipitates the formation of predator-prey oscillations. The same mechanism accounts for the area-diversity relationship obtained in 
experimental conditions, which are not standard, as well as in natural conditions.

Likewise, the same mechanism of competition accounts for competitive exclusion obtained in Gause's bottles and in natural conditions. Craver (2007, p. 126) thinks that knowing the inhibiting conditions is part of a complete characterization of the phenomenon. Although MacArthur and Wilson do not examine conditions that inhibit production of the phenomenon, the requirement to describe them could also be part of the normative account of ecological explanation.

Since mechanisms consist of entities and activities organized such that they produce the phenomenon under scrutiny (Craver, 2007, p. 6), mechanistic explanations in ecology must describe each of these elements. Entities are the parts of the mechanism, and they are expected to have stable properties, to be robust, to be ecologically plausible, and they could be used to intervene upon other entities and activities. Activities are what the entities do in the mechanism. This requires ecologists to describe the relevant behaviors of species and of inanimate components. Depending on the explanandum phenomenon, the relevant behavior could be feeding, mating, colonization, competitive interaction, etc. Activities of inanimate components could be ferrying insects to islands, dispersing seeds, providing shelter and habitat, or preventing dispersion, setting the stage for succession by wiping out flora and fauna, eliminating predators, or breaking seed dormancy. Both components and activities are organized actively, spatially and temporally, and mechanistic explanation has to specify that clearly. The dominant type of organization varies with the specific mechanism. Some mechanisms of interspecific competition for a limited food resource could be spatially organized, with organisms of different species feeding on the same food at different heights of a tree. In other cases, 
temporal organization plays the key role, as it happens with competing organisms that feed on the same resource at different times.

Mechanistic explanations in ecology are multilevel. They integrate information from several levels of reality because mechanisms producing ecological phenomena are multilevel. Components of mechanisms could come from various strata of the traditional hierarchy of levels that extends from molecules and cells, to organisms, populations, communities and all the way up to the biosphere, and include inanimate objects of various sizes, or even processes. A mechanism, such as the mechanism responsible for the colonization success of invasive species, could consist of entities from different strata of the traditional hierarchy: allelochemicals, populations, communities and soil. Since any mechanism is a mechanism of a phenomenon (Glennan, 2002), what entities make up a mechanism depends on the phenomenon being investigated (Craver, 2007). If the problem under scrutiny requires it, every mechanism component can be further examined to study its constituents. That is possible because components of the lower levels consist of components organized at even lower levels, which means that a mechanism can be composed of other lower level mechanisms. Scrutiny of the competitive success of invasive species can lead to examining the physiological mechanism producing allelochemicals, their molecular composition, and their growth-suppressing effect on other species. Similarly for processes, that can be seen as parts of mechanisms. Colonization and extinction are processes consisting of numerous and various lower-level components. Dispersions by wind, by debris, or by flight are lower-level components of colonization. Deaths due to interspecific competition, predation, or parasitism are lowerlevel components of extinction. One can further look at, say, dispersion by flight and 
examine the properties of lower level entities and activities, and their organization. Thus, one would examine how the anatomy and physiology of birds, or insects enables them to cover the distances between islands, and whether air currents aid them. At what lower level should mechanistic explanation stop? This question cannot be answered based on a hierarchy of levels that is independent of the explanandum phenomenon, but rather on a case-by-case basis and depending on the explanatory relevance of the lower level component (Craver, 2007, p. 191).

Mechanistic explanations must incorporate descriptions of the causal relationships between components of the ecological mechanism. These relationships should be understood along manipulationist lines. A component $\mathrm{X}$ causes $\mathrm{Y}$ provided that changes in $\mathrm{X}$ bring about changes in $\mathrm{Y}$, while all other paths from $\mathrm{X}$ to $\mathrm{Y}$ are blocked. Whenever possible, the specific activity of components should be specified. $\mathrm{X}$ might cause $\mathrm{Y}$ in virtue of the fact that $\mathrm{X}$ is in a symbiotic relationship with $\mathrm{Y}$ and facilitates $\mathrm{Y}$ 's acquisition of nutrients, or $\mathrm{X}$ might live as an ectoparasite on $\mathrm{Y}$ and deprive it of some of its energy. Causal interpretations in terms of activities and relationships that can be subject to manipulations should accompany phenomenological accounts of associations between species.

Good mechanistic explanations are expected to describe all of the relevant components and interactions between them, and none of the irrelevant ones (Craver, 2007, p. 140). Relevant components are at the intersection of analytic and synthetic experimental strategies. Experiments in ecology are traditionally categorized into laboratory experiments, field experiments, and natural experiments. Each of them has strengths and weaknesses, and ecologists combine evidence from all three types of 
experiments, or only two, usually field and laboratory experiments (Diamond, 1986). The requirement of constitutive relevance calls for a combination of these types of experiments so as to implement the mutual manipulability of component parts as a way of identifying the relevant components. This means that lab or field experiments that are designed on the analytic strategy are insufficient for ruling out irrelevant factors. Lab or field experiments based on the synthetic strategy must complement the former.

The kind of mechanisms that ecology and biogeography should be after according to MacArthur and Wilson are complex-systems mechanisms, as Glennan (2002, 2010) calls them. Complex-systems mechanisms are multiply realizable. They are reliable mechanisms and their repeated functioning produces regularities, which are described by generalizations, some of which are thought of as laws. The mechanism of the areadiversity pattern articulated by MacArthur and Wilson is such a reliable mechanism. Its reliable operation produces the species-area regularity that Schoener $(1976)^{8}$ and Lange (2005) describe as a law of ecology. An important consequence of the reliability of complex-mechanisms is that their behavior is predictable, and, consequently, one can formulate predictions of specific values and test hypotheses. By describing complexsystems mechanisms, ecology and biogeography become predictive sciences. This aspect connects the goal of describing mechanisms with the hypothetico-deductive method that both MacArthur and Wilson endorsed. If the description of the complex-systems mechanism is accurate, hypotheses derived from its model will not be invalidated by data. Hypotheses derived from inaccurate descriptions of mechanisms will be falsified.

${ }^{8}$ Apud Lomolino, et al. (2010, p. 513). 
Not all ecological phenomena are repeatable. Some of them are singular and of interest to ecologists. They are produced by ephemeral-mechanisms, as Glennan (2002, 2010) describes them. Ephemeral-mechanisms are not multiply-realizable. They are contingent, singular sequences of events that lead to a singular occurrence, such as the continental drift, the escape of the European gypsy moth caterpillars from Trouvelot's house in 1868 and the onset of the defaunation of hardwood forests in the Northeast of United States, and the introduction of Zebra mussel around 1985 to the Great Lakes. The norms of mechanistic explanation apply to ephemeral-mechanisms, as well. A good description of ephemeral-mechanisms specifies their components, their spatial or temporal organization, and the way they interact. Since ephemeral-mechanisms produce singular phenomena, whose occurrence is typically independent of ecologists, synthetic experimental strategies take precedence over analytical ones in guiding the identification of relevant components and of causal relationships between them. To study singular phenomena, ecologists have to simulate singular phenomena in laboratory or field experiments, which requires use of synthetic strategy. Employment of analytic strategies is confined to causal modeling that allows manipulation of values of variables that represent components and their spatial or temporal organization.

\subsection{A debate on the nature of ecology}

I showed in section 3 that MacArthur and Wilson saw explanation, as opposed to naturalists' detailed descriptions, related to the issue of establishing biogeography, i.e., ecology of geographic distributions of species as a science. Ecology becomes science 
once it explains patterns in nature. MacArthur and Wilson's use of the mechanistic approach to explain the area-diversity pattern implies a conception of science centered on describing mechanisms responsible for classes of similar phenomena. This view of science and the associated norms of explanation can help resolve a recent debate on the nature of ecology and its explanatory tools. The opposition between a conception of ecology that is content with documenting the complexities of nature, as MacArthur characterized it, and a conception that asks ecologists to explain repeated patterns has continued in the form of a tension between views conceiving of ecology as an historical science, and those that would like to see it formulate and use laws similarly to physics, and those that opt for description of mechanisms.

Lev Ginzburg and Mark Colyvan (Mark Colyvan \& Ginzburg, 2003a, 2003b; M. Colyvan \& Ginzburg, 2010; Ginzburg \& Colyvan, 2004) argue for a nomothetic research program for ecology. They think that exponential growth of populations, usually known as Malthus' law, is the first law of ecology and it is analogous to the first law of Newton in describing a default state from which actual populations deviate. And the deviation must be accounted for in terms of mechanisms. Marcel Weber (1999) offers a similar argument and account of the explanatory role of laws, but he thinks that the principle of competitive exclusion is the first law of ecology. Several ecologists (Berryman, 1999, 2003; Murray, 2000; Turchin, 2001) also argue in favor of laws of ecology, but they do not shed light on their explanatory role, but mostly look at the predictive role of laws. According to the opposite view, biology, including the discipline of ecology, is an historical science and cannot have laws like physics because its systems are far-from equilibrium, nonreversible and require historical explanations (Quenette \& Gerard, 1993). 
Ecology should be conceived of as a science of case studies, centered on revealing the causal nexus underlying a phenomenon, instead of laws (Shrader-Frechette, 2003; Shrader-Frechette \& McCoy, 1993). Ecology does not have laws like those of Newton that state how the universe works; it has only generalizations about observed regularities and that can be used to formulate models that describe the systems under scrutiny (O'Hara, 2005). Both its epistemology and its methodology make ecology an historical science (Brown, 2011). The other alternative that appears to be embraced by many ecologists, as suggested by their work and by formulations of research agendas for ecology (Simberloff, 2004; Sutherland, et al., 2013), is to describe mechanisms that underlie regularities (Lawton, 1999) and that are responsible for a group of phenomena (Tilman, 1987).

The idea of mechanism and the norms of mechanistic explanation implicit in $T I B$ could solve the dispute between the aforementioned views and provide a basis for methodological unification of ecology. In light of the foregoing account of explanation in ecology, I suggest that the basis of ecological explanations is mechanistic, but the specific mechanisms and phenomena under scrutiny are different, which makes the ecological enterprises appear different. When the focus of ecologists is on singular phenomena produced by ephemeral ecological mechanisms, they appear as formulating historical explanations. When ecologists turn their attention to complex-mechanisms of varying degrees of reliability and which, consequently, produce phenomena of various degrees of regularity, they are doing what most ecologists do: identifying mechanisms responsible for various groups of phenomena. However, when ecologists look for regularities across various domains of less restricted scope, they embark on a research 
program that appears nomothetic. However, even if such regularities are identified, their use in explanations cannot dispense of mechanism descriptions, as the work of Ginzburg and Colyvan, and Weber shows. Malthus' law and the principle of competitive exclusion describe default states that do not occur. To explain why observed populations deviate from the expected default conditions, one has to identify relevant mechanisms. Moreover, some ecologists explicitly claim that identification of regularities, such as allometries, is the first step toward revealing the underlying mechanisms. Explaining how the lowerlevel mechanisms are responsible for upper-level regularities is the goal of ecology (Brown, Gillooly, Allen, Savage, \& West, 2004).

\subsection{The new paradigm of insular biogeography and the old norms of explanation}

$T I B$ has not been able to account for all the patterns of insular biogeography. The accumulated problems have prompted projects to change the equilibrium paradigm. The new proposals call for amending the equilibrium principle of the theory to accommodate processes that are not at equilibrium or are nonequilibrium, as well as for acknowledgment of the importance of diverse features of species, islands and landscapes or seascapes in influencing immigration and extinction, and of in situ speciation and species interactions (Lomolino, 2000; Lomolino \& Brown, 2009). Yet the new paradigm of island biogeography appears to require the mechanistic approach. Lomolino and Brown suggest that the new theory of island biogeography should be multi-scale, speciesand process-based, and include system feedback (2009, p. 385). In terms of the mechanistic approach, for the theory to be multi-scale, it means that it should draw on 
information from multiple levels of mechanism, and which are not merely levels of size, or composition. The components cited in explanations could be of different sizes, and situated at different levels of the conventional hierarchy of levels of organization from cells to the biosphere. What components and from which levels should be cited depends on the problem being investigated. That the theory must be species- and process-based means that it must take into consideration the properties of species and islands that affect the basal processes of immigration, extinction, and evolution (Lomolino \& Brown, 2009, p. 385). Such a focus on properties of components and examining how changes in the properties affect the behavior that the components produce is a core requirement of mechanistic explanation and it derives from the definition of mechanisms. System feedback can take the form of interspecific interaction, evolutionary divergence and speciation, all of which can affect the basal processes and the capacities of species (Lomolino \& Brown, 2009, p. 385). On the mechanistic view, no examination of components would be complete without considering how they interact, what they do, or what happens to them. The requirement to take into account how interspecific interaction, divergence of populations over time and speciation influence insular biotas fits the mechanistic normative account. Thus, the new paradigm of island biogeography appears to be committed to the old mechanistic approach to explanation.

\section{Conclusion}

The foregoing examination has shown that $T I B$ is a book that was instrumental in initiating a paradigm in ecology. Based on other works of MacArthur and Wilson, I argued that they assumed a mechanistic philosophy of science. In light of that, and given 
two more recent accounts of mechanistic explanation, I showed in detail that $T I B$ implements a mechanistic approach to explanation. Since $T I B$ is a paradigmatic work of ecology, I used the analysis of its mechanistic approach to formulate a normative account of mechanistic explanation in ecology. Furthermore, I showed that a mechanistic perspective solves a dispute on the nature of ecology and that the new paradigm of insular biogegraphy assumes the mechanistic norms of explanation implicit in $T I B$.

\section{Acknowledgements}

I would like to thank Robert C. Richardson, Daniel Fouke, Iulian D. Toader, and Carl Friese, as well as session participants of the British Society for Philosophy of Science meeting in Dublin, 2010, and at the Midwest Workshop in Philosophy of Science and Philosophy of Mathematics, Fort Wayne, 2011, for comments, suggestions and criticism that helped me improve this article. The final version of the text was significantly shaped by the constructive review of an anonymous referee of the journal. Special thanks go to Diane Dunham for helping me improve the English expression of the article. I received financial support for this research from the Charles P. Taft Research Center at the University of Cincinnati and from the Research Council at the University of Dayton.

\section{References}

Bechtel, W. (2006). Discovering cell mechanisms: The creation of modern cell biology. Cambridge: Cambridge University Press.

Bechtel, W., \& Abrahamsen, A. (2005). Explanation: A mechanist alternative. Studies in History and Philosophy of Biological and Biomedical Sciences, 36, 421-441. 
Bechtel, W., \& Richardson, R. C. (1993). Discovering complexity: Decomposition and localization as strategies in scientific research. Princeton: Princeton University Press.

Berryman, A. A. (1999). Principles of population dynamics and their application. Cheltenham: Stanley Thornes.

Berryman, A. A. (2003). On principles, laws, and theory in population Ecology. Oikos, 103, 695-701.

Brown, B. (2011). Ecology as historical science. In K. deLaplante, B. Brown \& K. Peacock (Eds.), Philosophy of Ecology (pp. 251-284). Amsterdam: Elsevier.

Brown, J. H., Gillooly, J. F., Allen, A. P., Savage, V. M., \& West, G. B. (2004). Toward a metabolic theory of ecology. Ecology, 85, 1771-1789.

Cody, M. L., \& Diamond, J. M. (1975). Preface. In M. L. Cody \& J. M. Diamond (Eds.), Ecology and evolution of communities. Cambridge: Belknap Press of Harvard University Press.

Colyvan, M., \& Ginzburg, L. R. (2003a). The Galilean turn in population ecology. Biology and Philosophy, 18, 401-414.

Colyvan, M., \& Ginzburg, L. R. (2003b). Laws of nature and laws of ecology. Oikos, 101, 649-653.

Colyvan, M., \& Ginzburg, L. R. (2010). Analogical thinking in ecology: looking beyond disciplinary boundaries. The Quarterly Review of Biology, 85, 171-182.

Craver, C. F. (2006). When mechanistic models explain. Synthese, 153, 355-376.

Craver, C. F. (2007). Explaining the brain: Mechanisms and the mosaic unity of neuroscience: Oxford University Press.

Darden, L. (2006). Reasoning in biological discoveries: Essays on mechanisms, interfield relations, and anomaly resolution. Cambridge: Cambridge University Press.

Diamond, J. (1986). Overview: Laboratory experiments, field experiments, and natural experiments. In J. Diamond \& T. J. Case (Eds.), Community ecology (pp. 3-22). New York: Harper \& Row.

Fretwell, S. D. (1975). The impact of Robert MacArthur on ecology. Annual Review of Ecology and Systematics, 6, 1-13.

Ginzburg, L. R., \& Colyvan, M. (2004). Ecological orbits: How planets move and populations grow. New York: Oxford University Press.

Glennan, S. (1996). Mechanisms and the nature of causation. Erkenntnis, 44, 49-71.

Glennan, S. (2002). Rethinking mechanistic explanation. Philosophy of Science, 69, S342-S353.

Glennan, S. (2010). Ephemeral mechanisms and historical explanation. Erkenntnis, 72, 251-266.

Gotelli, N. J. (2008). A primer of ecology (4 ed.). Sunderland: Sinauer Associates, Inc.

Haila, Y., \& Järvinen, O. (1982). The role of theoretical concepts in understanding the ecological theatre: A case study on island biogeography. In E. Saarinen (Ed.), Conceptual issues in ecology (pp. 261-278). Dordrecht, Hingham, MA: D. Reidel.

Ishida, Y. (2007). Patterns, models, and predictions: Robert MacArthur's approach to ecology. Philosophy of Science, 74, 642-653.

Kingsland, S. E. (1995). Modeling nature: episodes in the history of population ecology (2nd ed.). Chicago: University of Chicago Press. 
Kolata, G. B. (1974). Theoretical ecology: Beginnings of a predictive science. Science, $183,400-401,450$.

Lange, M. (2005). Ecological laws: what would they be and why would they matter? Oikos, 110, 394-403.

Lawton, J. H. (1999). Are there general laws in ecology? Oikos, 84, 177-192.

Levins, R. (1966). The strategy of model building in population biology. American scientist, 54, 421-431.

Lomolino, M. (2000). A call for a new paradigm of island biogeography. Global Ecology and Biogeography, 9, 1-6.

Lomolino, M. V., \& Brown, J. H. (2009). The reticulating phylogeny of island biogeography theory. The Quarterly Review of Biology, 84, 357-390.

Lomolino, M. V., Brown, J. H., \& Sax, D. F. (2010). Island biogeography theory. Reticulations and reintegration of "A Biogeography of the Species". In J. B. Losos \& R. E. Ricklefs (Eds.), The theory of island biogeography revisited (pp. 13-51). Princeton: Princeton University Press.

Lomolino, M. V., Riddle, B. R., Whittaker, R. J., \& Brown, J. H. (2010). Biogeography. Sunderland: Sinauer Associates Inc.

Losos, J. B., \& Ricklefs, R. E. (2010). Preface. In J. B. Losos \& R. E. Ricklefs (Eds.), The theory of island biogeography revisited (pp. xi-xiv). Princeton: Princeton University Press.

MacArthur, R. H. (1957). On the relative abundance of bird species. Proceedings of the National Academy of Sciences of the United States of America, 43, 293-295.

MacArthur, R. H. (1972). Geographical ecology; patterns in the distribution of species. New York: Harper \& Row.

MacArthur, R. H., \& Wilson, E. O. (1963). An equilibrium theory of insular zoogeography. Evolution, 17, 373-387.

MacArthur, R. H., \& Wilson, E. O. (1967). The theory of island biogeography. Princeton: Princeton University Press.

Machamer, P., Darden, L., \& Craver, C. F. (2000). Thinking about mechanisms. Philosophy of Science, 67, 1-25.

May, R. M. (2010). Forward. In J. B. Losos \& R. E. Ricklefs (Eds.), The theorey of island biogeography revisited (pp. vii-ix). Princeton: Princeton University Press.

Murray, B. G. J. (2000). Universal laws and predictive theory in ecology and evolution. Oikos, 89, 403-408.

Nagel, E. (1961). The structure of science: problems in the logic of scientific explanation. New York: Harkourt, Brace and World, Inc.

O'Hara, R. B. (2005). The anarchist's guide to ecological theory. Or, we don't need no stinkin' laws. Oikos, 110, 390-393.

Odenbaugh, J. (2011). Philosophical themes in the work of Robert H. MacArthur. In K. deLaplante, B. Brown \& K. A. Peacock (Eds.), Philosophy of Ecology (pp. 109128). Oxford: Elsevier.

Pâslaru, V. (2009). Ecological Explanation between Manipulation and Mechanism Description. Philosophy of Science, 76, 821-837.

Pearl, J. (2000). Causality: Models, Reasoning, and Inference. Cambridge: Cambridge University Press. 
Popper, K. R. (1974). Scientific reduction and the essential incompleteness of all science. In F. J. Ayala \& T. Dobjhansky (Eds.), Studies in the philosophy of biology: reduction and related problems (pp. 259-284). Berkeley and Los Angeles: University of California Press.

Quenette, P. Y., \& Gerard, J. F. (1993). Why biologists do not think like Newtonian physicists. Oikos, 68, 361-363.

Salmon, W. C. (1984). Scientific explanation and the causal structure of the world. Princeton: Princeton University Press.

Schoener, T. W. (1976). The species-area relation within archipelagos: models and evidence from island land birds. In Proceedings of the XVI International Ornithological Congress (Vol. 6, pp. 629-642). Canberra: Australian Academy of Science.

Schoener, T. W. (1986). Mechanistic approaches to community ecology: A new reductionism? American Zoologist, 26, 81-106.

Schoener, T. W. (2008). Island biogeography. In S. E. Jørgensen \& B. D. Fath (Eds.), Encyclopedia of ecology (Vol. 3, pp. 2040-2050). Amsterdam: Elsevier.

Shrader-Frechette, K. (2003). Ecology. In D. Jamieson (Ed.), A companion to environmental philosophy (pp. 304-315). Malden: Blackwell Publishers

Shrader-Frechette, K. S., \& McCoy, E. D. (1993). Method in ecology: strategies for conservation. Cambridge: Cambridge University Press.

Simberloff, D. (2004). Community ecology: is it time to move on? The American Naturalist, 163, 787-799.

Simberloff, D. S. (1974). Equilibrium theory of island biogeography and ecology. Annual Review of Ecology and Systematics, 5, 161-182.

Simberloff, D. S., \& Wilson, E. O. (1969). Experimental zoogeography of islands: The colonization of empty islands. Ecology, 50, 278-296.

Simberloff, D. S., \& Wilson, E. O. (1970). Experimental zoogeography of islands. A twoyear record of colonization. Ecology, 51, 934-937.

Sismondo, S. (2000). Island biogeography and the multiple domains of models. Biology and Philosophy, 15, 239-258.

Spirtes, P., Glymour, C., \& Scheines, R. (2000). Causation, prediction, and search. Cambridge: The MIT Press.

Sterelny, K., \& Griffiths, P. E. (1999). Sex and death: An introduction to philosophy of biology. Chicago: University of Chicago Press.

Sutherland, W. J., Freckleton, R. P., Godfray, H. C. J., Beissinger, S. R., Benton, T., Cameron, D. D., Carmel, Y., Coomes, D. A., Coulson, T., \& Emmerson, M. C. (2013). Identification of 100 fundamental ecological questions. Journal of Ecology, 101, 58-67.

Tilman, D. (1987). The importance of the mechanisms of interspecific competition. The American Naturalist, 129, 769-774.

Turchin, P. (2001). Does population ecology have general laws? Oikos, 94, 17-26.

Web of Science database. (n.d.).

http://apps.webofknowledge.com/WOS_GeneralSearch_input.do?highlighted tab $=$ WOS\&product $=$ WOS\&last prod $=$ WOS\&SID $=4$ AJi7BXdeJP4P2XaCzw\&searc h_mode $=$ GeneralSearch. (Accessed 9 August 2013) 
Weber, M. (1999). The aim and structure of ecological theory. Philosophy of Science, 66, 71-93.

Whittaker, R. J. (1998). Island biogeography: ecology, evolution, and conservation. Oxford: Oxford University Press.

Whittaker, R. J. (2002). Island biogeography. In M. D. Pagel (Ed.), Encyclopedia of evolution. Oxford: Oxford University Press.

http://www.oxfordreference.com/view/10.1093/acref/9780195122008.001.0001/a cref-9780195122008-e-40?rskey=LDSBDs\&result=31. (Accessed 17 August 2013)

Wilson, E. O. (1971). The insect societies. Cambridge: Harvard University Press.

Wilson, E. O. (1977). Biology and the social sciences. Daedalus, 106, 127-140.

Wilson, E. O. (1978). What is sociobiology? Society, 15, 10-14.

Wilson, E. O. (1994). Naturalist. Washington: Island Press.

Wilson, E. O. (2009). Island Biogeography in the 1960s. In J. B. Losos \& R. E. Ricklefs (Eds.), The theory of island biogeography revisited (pp. 1-12). Princeton: Princeton University Press.

Wilson, E. O. ( 2000 [1975]). Sociobiology: the new synthesis. Cambridge: The Belknap Press of Harvard University Press.

Wilson, E. O., \& Simberloff, D. S. (1969). Experimental zoogeography of islands: Defaunation and monitoring techniques. Ecology, 50, 267-278.

Wimsatt, W. C. (1997). Aggregativity: Heuristics strategies for finding emergence. Philosophy of Science, 64, S372-S384.

Woodward, J. (2003). Making things happen: A theory of causal explanation. New York: Oxford University Press. 
